\title{
Imágenes en tres dimensiones
}

\author{
Dr. Manuel Carlos Fernández Sánchez
}

Profesor de Tecnología de los Medios Audiovisuales

Universidad de Sevilla

Después de realizar un breve estudio sobre la tridimensionalidad en el arte desde las pinturas rupestres hasta la actualidad, nos internamos en la investigación sobre los aspectos biológicos y psicológicos de la visión en tres dimensiones, para centrarnos finalmente en las tradicionales y nuevas tecnologías que aplican la visión estereoscópica como son el cine en relieve, la realidad virtual o la holografía.

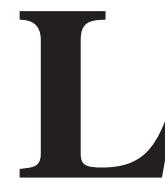

a humanidad, desde su propio nacimiento, ha pretendido representar las imágenes de su alrededor en forma tridimensional. Ya lo intentaron los hombres primitivos. Eso hicieron los primeros pintores en las famosas cuevas de Lascaux, datadas hace 16.000 años. En la cueva francesa, bajo la luz tenue de la antorcha, pueden tomar una calidad tridimensional las representaciones de ciervos, búfalos u otras escenas de animales. Para muchos esto no es fruto de la casualidad sino que fueron pintadas deliberadamente en tres dimensiones.

El interés por el fenómeno de la tridimensionalidad visual se remonta a la Grecia clásica. En el siglo III antes de Cristo el matemático griego Euclides (c.295 a. J.C.), estudió en su tratado titulado Óptica la relación entre la visión estereoscópica y el hecho de que los seres humanos dispongan de dos ojos. Ya en el siglo II de nuestra era, el médico griego Galeno describiría también lo que supuso una profundización de una teoría razonada de la visión de la perspectiva a través de los dos ojos. Supo, por observación, que si se cerraba un ojo, la imagen del entorno cambiaba ligeramente.

También otras mentes de una gran altura de pensamiento como Leonardo da Vinci, Kepler e incluso Descartes han estudiado a lo largo de la historia cuestiones relacionadas en cómo representar tres dimensiones en una superficie plana.

Sería en 1833 cuando se descubre un dispositivo notablemente sencillo que reproduce la tridimensionalidad. Lo llamarían estereoscopio. El estereoscopio de Charles Wheatstone, físico escocés que trabajó antes de que se inventara la 
fotografía, fue el primero y principal avance que conduciría a toda una larga cadena de aparatos e invenciones para ver en relieve.

En lo que respecta a la imagen tridimensional, Wheatstone informó que las pequeñas diferencias entre las imágenes proyectadas a los dos ojos ofrecen una sensación vívida de la profundidad del espacio en tres dimensiones. Dicho aparato constaba de dos espejos colocados en ángulo con respecto al observador, y una imagen situada frente a cada espejo. Esas imágenes eran dibujos y figuras geométricas. El escocés llegó a la conclusión de que las diferencias visuales que presentan ambos ojos eran el origen de la percepción en relieve.

"A este fenómeno dio el nombre de stereopsis, que en griego significa "sólido" y "visión”." (Richardson, 1995, p. 60)

Cuando se introdujo el daguerrotipo, a principios del siglo pasado, se aplicó rápidamente a la estereoscopia, lo que aportó un éxito insospechado a la percepción técnica de la imagen en tres dimensiones en Europa.

Pocos años después, David Brewster diseñó y construyó la primera cámara fotográfica estereoscópica, con la que obtuvo las primeras fotografías en relieve. Construyó también un visor con lentes para observarlas.

"Al principio, Brewster hacía sus fotografías con una cámara monocular cuyo objetivo se desplazaba horizontalmente sobre una plancheta graduada. Luego la sustituyó por una cámara binocular que al obtener sincrónicamente las dos imágenes le permitía realizar retratos estereoscópicos” (De Castro, 1998, Internet).

Los motivos debían ser estáticos, sin ningún tipo de movimiento para que la tridimensionalidad funcionara lo mejor posible.

Todo tipo de estudiosos, hoy en día, como arqueólogos, topógrafos, geólogos, químicos y el ejército emplean fotografías e ilustraciones tridimensionales estereoscópicas para facilitar el estudio del tema que les interesa. Una de las aplicaciones prácticas de la estereoscopia es la visualización del relieve terrestre mediante fotografías aéreas. Se utiliza pues para la cartografía. También muchos geólogos, así como expertos forestales o planificadores urbanos, y otros especialistas relacionados con las ciencias de la Tierra utilizan el estereoscopio.

Durante los años noventa, los avances en el mundo de la informática están permitiendo presentar imágenes en tres dimensiones de gran calidad en pantallas de ordenador y utilizarlas para todo tipo de presentaciones. Los ordenadores permiten generar imágenes espectaculares de síntesis en relieve, para aplicaciones científicas, industriales o de entretenimiento.

Recientemente la NASA ha utilizado la estereoscopia como una herramienta para ver en 3D y analizar las imágenes de Marte enviadas por sondas espaciales. 
También la NASA ha obtenido numerosas vistas en tres dimensiones de fotografías de la Tierra obtenidas desde satélites. En medicina se utiliza la estereoscopia para la enseñanza, el diagnóstico o como ayuda en las intervenciones. No es una novedad que lupas y microscopios de precisión cuenten con visión estéreo desde hace tiempo. En el arte de la pintura se ha utilizado también el principio de la estereoscopia.

En la pintura, la fotografía, el cine y la televisión encontramos tres dimensiones, pero sólo dos de ellas son reales: el largo y el ancho de la pantalla. ¿Y la tercera dimensión? Apreciamos el relieve mediante la perspectiva. Un cuadro tiene una tercera dimensión gracias a la perspectiva. Podríamos definir la perspectiva como la técnica de representar en una superficie plana un objeto de tres dimensiones. La perspectiva representa una escena de tres dimensiones en dos solamente. Es un artilugio técnico basado en las leyes de la geometría.

Comenzando el siglo XV, en la ciudad de Florencia, el arquitecto y escultor Filippo Brunelleschi descubrió la perspectiva lineal, formalizada en 1435 por su discípulo Leon Battista Alberti. También durante el Renacimiento, Piero della Francesca (c. 1415-1493) escribió un tratado sobre la perspectiva. Este pintor italiano, fue uno de los más grandes artistas del Renacimiento y estudió perspectiva en las obras de Paolo Uccello. Sus estudios teóricos los aplicó prácticamente en su pintura en muchos de los cuadros que plasmó.

La imagen retiniana, entre otras cosas, es binocular, mientras que la perspectiva se enclava dentro de la monocularidad, al igual que la fotografía tradicional. La cámara de cine, de vídeo y de televisión son herederas de este sistema. En el cine y la televisión hay varios tipos de perspectiva, algunos comunes con otras artes:

- La perspectiva lineal es común con el dibujo. Al menos en Occidente desde el Renacimiento hasta ahora es el procedimiento canónico, para representar las tres dimensiones del espacio en un plano de únicamente dos.

- La perspectiva cromática o tonal, es común con la pintura, y es otro procedimiento, también válido, para incrementar la sensación de profundidad en el espacio mediante los distintos tonos de color.

- La perspectiva aérea, es propia del cine, la televisión y la fotografía. En la pintura fue un experto en esta técnica Velázquez. La perspectiva aérea es un efecto general de profundidad creado en la fotografía de un paisaje por la bruma. En ella, los objetos próximos se ven nítidos y los objetos lejanos resultan borrosos. Hay, generalmente, en el aire, una cierta cantidad de bruma (vapor de agua, humo, polvo) y la cantidad de ella aumenta con la distancia hacia el infinito. El ojo acepta la bruma como un indicio de profundidad y espaciosidad.

- La perspectiva cinética es propia del cine y la televisión. Se debe al movimiento en diagonal de los objetos. Es el procedimiento empleado por los hermanos Lumiñre en los comienzos del cine. Un ejemplo de ello es la cinta 
Llegada de un tren a la estación. El tren que se desplaza en oblicuo por la pantalla se precipita desde el fondo hacia los espectadores que creen que se les viene encima. La perspectiva cinética es muy utilizada actualmente en el cine de acción.

Tras hablar del relieve en el arte, refirámonos ahora a la ciencia. Hablemos brevemente de algunos conceptos de la psicología de la percepción y la visión en relieve y de la moderna neurociencia para poder comprender las bases de las nuevas tecnologías de la imagen en tres dimensiones.

Vivimos en un mundo de cuatro dimensiones. 0 al menos lo percibimos en esa forma. La dimensión del tiempo pudo congelarse en el siglo pasado con el invento del daguerrotipo, luego perfeccionado como fotografía. Después, a finales del mismo siglo, ese tiempo tecnológico congelado adquiere movimiento. Pero esos inventos decimonónicos, llegados hasta hoy día, son limitados con respecto a las dimensiones espaciales que presentan. El cine tradicional desarrolla un espacio en dos dimensiones: largo y alto y simula la tercera, la profundidad, mediante las técnicas de la perspectiva plana, ya utilizadas en la pintura desde el Renacimiento.

Para que exista la sensación de tridimensionalidad espacial no solo son necesario dos ojos, dos retinas. Sólo con eso veríamos doble. Y sin embargo no es así. Para que exista la tridimensionalidad también es necesario el cerebro. Él es quien integra, totaliza y restituye la tridimensionalidad. No por el sólo hecho de disponer de un par de órganos para la visión ésta tendrá apariencia tridimensional. Ha de ocurrir también que los ojos estén situados mirando hacia el frente. En los humanos, la percepción de la profundidad comienza a manifestarse aproximadamente a los dos meses de vida. A los cinco o seis años, el niño ya ha desarrollado esta facultad.

Cuando los ojos enfocan en un objeto, convergen. Esta convergencia binocular llega a producirse por la acción de los músculos que controlan el movimiento del ojo e indica la distancia relativa con respecto a ese objeto. Cuanto mayor sea la convergencia más cercano está el objeto que se mira.

El cerebro se apoya en la retroalimentación propioceptiva. La propiocepción es simplemente la percepción por parte del cerebro del estado del cuerpo, por ejemplo, su postura u orientación, o en nuestro caso, la posición de los músculos del ojo cuando se produce la convergencia.

La visión estéreo o binocular es únicamente una de las tantas maneras en la que vemos profundidad. La convergencia sólo funciona para objetos relativamente cercanos. Cuanto más alejado está el objeto las imágenes se hacen tan pequeñas que son prácticamente idénticas. En realidad somos monoculares para distancias superiores a seis metros. A partir de esa distancia nuestro organismo hace uso de otras señales monoculares que también proporcionan en la visión cercana una valiosa información complementaria.

Por ello, el cerebro ha de recurrir también a la paralaje binocular, que es la información enviada por cada imagen producida en cada ojo. Estos dos factores, 
la convergencia y el paralaje, combinados, forman la base de la estereopsis, o sensación binocular de la profundidad. El cerebro reconstruye la tridimensionalidad a partir de las dos imágenes, ligeramente diferentes, que le llegan de los ojos.

A manera de resumen podemos decir que el hombre es capaz de apreciar utilizando la visión binocular, las distintas distancias y los diversos volúmenes en el área que le rodea. La distancia interpupilar es de $65 \mathrm{~mm}$. normalmente, pero puede llegar a variar entre los 75 y los $45 \mathrm{~mm}$. A mayor separación entre los ojos, mayor es la distancia a la que apreciamos el efecto de relieve. El efecto obtenido con una separación interocular mayor que la habitual es que los objetos parecen más pequeños de lo normal, a lo que se denomina liliputismo, y la técnica se llama hiperestereoscopia. Si se reduce la distancia interocular, como sucede en las macrofotografías o en los microscopios, la técnica se denominará hipoestereoscopia.

Hasta ahora las distintas técnicas artificiales, extensiones de nuestros sentidos como diría el filósofo, humanista y teórico Marshall McLuhan, desarrolladas por el hombre, han sido intentos, hoy día bastantes desarrollados, pero aún imperfectos, de copiar, como no podía ser menos, el sistema perceptual humano. Pero aún esa copia queda relegada a nivel de la retina, si bien comienzan a surgir tímidos intentos de ampliar a niveles técnicos los conocimientos científicos todavía insuficientes sobre la percepción no ya del ojo sino del cerebro.

La pintura, tras el Renacimiento, y el estudio de la perspectiva, presentan modelos perceptuales del mundo en tres dimensiones. Pero serán las técnicas fotográficas estereoscópicas y posteriormente el cine en relieve los que más modernamente nos hacen intuir las imágenes en profundidad de volúmenes.

A ello se han sumado ahora otras nuevas tecnologías de la comunicación, aún en desarrollo, como la realidad virtual. Los nuevos resultados que se están obteniendo de la estereografía aplicada a la realidad virtual son fruto de los conocimientos de las múltiples disciplinas que han estudiado hasta hoy en día la percepción y la obtención técnica del relieve.

Los primeros sistemas de cine en relieve se basaban en la estereoscopia por anaglifos. La palabra anaglifo procede del griego y significa "tallado en relieve". Se utiliza la palabra en el arte para designar, según el Diccionario de la lengua española, el "vaso u otra obra tallada, de relieve abultado".

La estereoscopia por anaglifos en el arte fotográfico «es un sistema especial de fotografías estereoscópicas de dos imágenes, una con coloración roja y la otra azul verdosa, que se superponen, ligeramente desplazadas o desfasadas, en la copia fotográfica» (Diccionario Enciclopédico Larousse, 1990). Para que el procedimiento cinematográfico de la estereoscopia funcione adecuadamente ha de ser necesario en primer lugar que el ojo derecho y el izquierdo reciban sólo y únicamente la imagen destinada a cada uno de ellos. Sin embargo, en la técnica cinematográfica, al contrario que en la fotográfica, el procedimiento se complica 
algo al ser necesario, además, proceder a la separación de las imágenes proyectadas.

La estereoscopia cinematográfica es proveniente de la técnica de la fotografía y estuvo muy en boga a nivel experimental sin resultados en la primera etapa del cine. Y ya entrados los años veinte se comercializaría a gran escala. A partir de 1935 surgen sistemas comerciales como el Audioscopia. En 1937, la MGM produjo una comedia titulada The third dimension murder (Asesinato en la tercera dimensión), título muy apropiado para el sistema técnico utilizado, filmada con una cámara especialmente diseñada y que aún seguía siendo un inoperante procedimiento bicolor.

La creación de la estereoscopia por anaglifos consiste en la proyección de dos imágenes en blanco y negro coloreadas una en verde-azulado y la otra en rojo. La imagen del ojo izquierdo, por ejemplo, se proyecta en la pantalla cinematográfica a través de un gel rojo en el objetivo del proyector y ya que el ocular izquierdo del usuario también está cubierto de un gel rojo, la imagen derecha es invisible para el ojo derecho. El otro proyector lleva su correspondiente gel verde.

Para su recepción, el espectador debe llevar unas gafas con un filtro rojo y otro azul-verdoso respectivamente. El filtro verde-azul impide el paso de las radiaciones rojas, permitiendo únicamente el de la imagen coloreada en azul-verde. El filtro rojo actúa a la inversa, es decir, sólo deja pasar la imagen coloreada en rojo.

La fusión mental psicológica del cerebro hace que las imágenes sean percibidas en negro sobre una mezcla de rojo y verde-azulado. Esa mezcla da en principio blanco. Sin embargo, en la práctica, el tono del fondo oscila permanentemente entre el rojo y el azul-verdoso.

La ventaja del método anaglífico es su bajo coste debido a que las dos imágenes de un sólo color pueden formarse con facilidad sobre una película de dos capas. Las gafas visionadoras de gelatina también son baratas. Una desventaja es que aun usando los mejores colorantes disponibles se produce una cierta difusión de un ojo al otro, a lo que se llama falta de extinción, y que llega a producir una adulteración desagradable de la imagen estéreo. Igualmente el hecho de que cada ojo vea una imagen con diferente tono de color causa lo que se denomina competición de retina, que llega a producir en muchos espectadores dolor de cabeza de mayor o menor intensidad a los pocos minutos y en otros hasta sensación aguda de náuseas.

El invento de los anaglifos ha sido sustituido más modernamente por la mejor técnica de la estereoscopia por luz polarizada que no altera los colores. La polaridad de la luz es una característica que en general es invisible para el ojo humano, pero se pueden preparar filtros transparentes que dejen pasar sólo la luz de una polaridad. Muchos insectos, entre ellos las abejas, así como ciertos arácnidos y crustáceos, son capaces de observar la luz polarizada del sol, por las 
características biológicas de sus ojos. En sus aparatos visuales existen dispositivos, en medidas microscópicas, por medio de los cuales saben inmediatamente el plano de vibración de la luz polarizada. Esto es de una gran importancia para su capacidad de orientación.

En 1928 el inventor Edwin Land, de la Polaroid, descubrió y creó, entre las dos guerras mundiales, los filtros polarizados, muy utilizados hoy en día por la técnica fotográfica. En fotografía se utilizan modernamente filtros polarizados, que tienen un aspecto grisáceo y poseen unas propiedades extras poco habituales que proporcionan aplicaciones diversas en fotografía y cinematografía. En su aplicación fotográfica, los filtros polarizados se pueden usar para eliminar la luz del día que se refleja en cualquier superficie, generalmente cristales o un lago, también puede alterarse el azul del cielo, oscureciéndolo o aclarándolo, utilizando un filtro polarizador. Para ello hay que hacer girar el filtro hasta obtener la intensidad de azul en el cielo que desee el fotógrafo, destacando las nubes sobre el cielo azul.

En la cinematografía estereoscópica por filtros polarizadores las dos imágenes, derecha e izquierda, se proyectan a través de dos filtros polarizantes con orientaciones perpendiculares, en una pantalla metalizada que conserva la dirección de polarización. La imagen para el ojo derecho es polarizada en un sentido, por ejemplo en vertical, mientras que la imagen izquierda se polariza en horizontal.

La estereoscopia por luz polarizada presenta dos grandes ventajas sobre los anaglifos, como es una importante reducción de la fatiga visual y la posibilidad del color en las imágenes. Históricamente la Warner produjo, entre lo más notable, el título Crimen perfecto (Dial M for Murder), de Alfred Hitchcock, en 1952, en 3D por luz polarizada, así como Los crímenes del museo de cera, el año siguiente. El cine en relieve de esta época disfrutó también de breve popularidad. A ésta desaparición contribuyó enormemente la aparición del Cinemascope. Perkins (1985, p. 55), mediados los años setenta, en su libro El lenguaje del cine, vislumbraba la posibilidad de que el cine estereoscópico siguiera apareciendo esporádicamente hasta que sus problemas técnicos fueran definitivamente resueltos.

Efectivamente, los científicos de la imagen siguieron intentándolo y perfeccionando las soluciones a los problemas técnicos que presentaban. Pero para ello han tenido que pasar años hasta que nuevas tecnologías diferentes, todavía complicadas, han venido en su ayuda.

Más recientemente se ha puesto en práctica un nuevo método de cine en relieve basado en la estereoscopia por obturación. La creación de este nuevo método ha hecho realidad el sistema de imágenes alternativas. Cuando se proyecta la imagen para el ojo derecho, el obturador del ojo izquierdo se cierra y, viceversa. Al proyectarse la imagen para el ojo izquierdo, el obturador del ojo derecho es el que está cerrado. Las señales sincronizadas desde proyección se envían por rayos infrarrojos, de forma que las gafas no necesitan cables, pero son voluminosas y pesadas, si bien no restringen los movimientos de los espectadores. 
En los mejores sistemas cada 1/60 de segundo se proyecta el cuadro para el ojo derecho y cada 1/60 de segundo se exhibe la vista para el ojo izquierdo, de tal forma que las vistas son alternadas y muy rápidas en el tiempo por lo cual en el cerebro del espectador se fusionan en una sola imagen con representación mental tridimensional.

El nuevo sistema Imax rueda en negativo de $65 \mathrm{~m} / \mathrm{m}$, con 15 perforaciones, dejando por tanto un área negativa casi nueve veces mayor que la estándar de 35 milímetros. La pantalla puede ser de 20 a 30 metros de altura, equivalente a un edificio de 7 u 8 pisos. Necesita pues un gran espacio debido al enorme tamaño de la pantalla. Una variante del sistema Imax es el formato Omnimax. Éste viene a utilizar el mismo sistema que Imax. La diferencia estriba en que requiere lentes grandes angulares para cubrir un área ovalada del negativo. Las copias se proyectan en pantalla esférica en forma de cúpula. El formato es actualmente de los más espectaculares.

En los sistemas Imax $3 D$ los problemas habituales de proyección tridimensional se han reducido al máximo. Se han vuelto a diseñar gafas con ventana de mayor tamaño, para que se ajusten a las grandes pantallas. También se usan filtros polarizadores de mayor eficacia. En cuanto a la proyección en Imax en relieve, en un principio se utilizaron dos proyectores independientes sincronizados, pero más tarde se construyó uno con doble transporte de película, con los objetivos situados uno sobre otro y muy próximos entre sí.

El moderno cine en relieve sí produce la sensación estereoscópica que había predicho Aldous Huxley en su celebrada novela Un mundo feliz, aun cuando todavía quedan aspectos sin resolver. Y es que el cine, el cine del futuro, aún está por inventar definitivamente.

Actualmente se están llevando a la práctica una serie de experimentos en relación a la televisión tridimensional. En televisión o vídeo para llegar a obtener una percepción estereoscópica, o con la apariencia de tridimensional, es necesario disponer, como en la fotografía y el cine en relieve, de dos imágenes. Lo que diferencia al sistema televisivo es que esas dos imágenes aquí son emitidas alternadas en semicuadros. En lugar de emitir cincuenta semi-imágenes completas se emiten la mitad, o sea, veinticinco semi-imágenes para el ojo izquierdo y otras veinticinco para el derecho. A ello hay que añadir también unas gafas polarizadas, que pueden estar controladas por un mando de rayos infrarrojos, permitiendo la visión sincrónicamente con la imagen emitida.

La realidad virtual es una tecnología informática que nos permite sumergimos en mundos artificiales construidos por el hombre con ayuda de ordenadores gráficos. Es una nueva tecnología, todavía primitiva, que asegura una relación, cada vez más íntima, entre hombre y máquina. En realidad virtual los periféricos tradicionales, teclado y monitor, son sustituidos por el casco de visualización estereoscópica, y el guante de datos. Sobre lo que deben o no incorporar los 
sistemas de realidad virtual no existen reglas fijas y específicas. Sin embargo, los mejores sistemas utilizan tres elementos básicos: la inmersión, la navegación y la manipulación o interacción.

Las técnicas de inmersión física en la imagen se consiguen por medio de cascos estereoscópicos y en un futuro por láseres retinianos que provocan la sensación de haber "pasado a través del espejo", al otro lado de la pantalla. Algunos sistemas de realidad virtual utilizan un casco con dos pantallas en miniatura en vez de una pantalla normal de ordenador, para así estimular el sentido de la vista. Mostrando a cada ojo una imagen imperceptiblemente distinta, las dos pantallas del casco aprovecha el fenómeno de la paralaje binocular para crear el efecto tridimensional, añadiendo así más realismo al mundo virtual.

El casco también puede tener en cuenta los movimientos de la cabeza, suministrando al ordenador un flujo de datos respecto a su posición y orientación en un espacio tridimensional. A su vez, el ordenador ajusta la pantalla del casco, produciendo un estímulo visual que está sincronizado con los movimientos de cabeza.

Algunos sistemas de realidad virtual utilizan dispositivos de entrada adicionales, como guantes que perciben la orientación y posición de las manos. Los guantes de datos actúan igual que el casco con pantallas, suministrando al ordenador más datos.

La inmersión lleva al espectador al engaño y le hace pensar que se encuentra en una realidad alternativa, mientras que la navegación le da la oportunidad de explorarla. La navegación es la habilidad de desplazarse dentro del ciberespacio generado por el ordenador, explorarlo e interactuar con él a voluntad. Naturalmente esto no significa que en realidad vaya a alguna parte. Es sólo la sensación de que puede moverse dentro lo que hace que su entorno sea «virtual».

Los dispositivos más eficaces y asombrosos de entrada de datos para los sistemas de realidad virtual, son los cascos. Los cascos gestionan tanto la información de entrada como la de salida y se acoplan a la cabeza del usuario o cuelgan del techo por encima de ella. El casco verifica los movimientos laterales y verticales de la cabeza y envía los datos sobre su posición al ordenador. El ordenador usa esos datos para crear imágenes estereoscópicas en el entorno virtual. Las imágenes estereoscópicas se envían a un par de pantallas miniaturizadas, que presentan un mundo tridimensional.

Tres funcionalidades básicas caracterizan al casco de visualización: aislar al sujeto del mundo exterior al ocupar la casi totalidad del campo visual, proporcionar una visión en relieve por estereoscopia y hacer que la imagen reaccione en función de los movimientos y los desplazamientos de la cabeza. De ahí la sensación de inmersión en un universo tridimensional cerrado.

La holografía es el sistema que mejor resuelve la visión en relieve sin la mediación técnica de las gafas y ello lo hace de una forma espectacular y distinta a todos los métodos que hemos visto hasta ahora. La holografía es un método 
autoestereoscópico en el que los fundamentos científicos de su tecnología difiere de todos los demás.

Holograma es una palabra científica compuesta por dos elementos composicionales. «Holo», procedente del latín, y a su vez del griego, significa «todo»o «entero». «Grama», procedente del griego «gramma» sería «letra», «escrito» o «gráfico». Por lo tanto, la palabra holograma significa escrito total o gráfico total. Es pues un término que traduce exactamente su intención semántica y tecnológica.

Pero a diferencia de lo que sucede con las imágenes fotográficas estereoscópicas, la imagen holográfica posee una profundidad y paralaje continuo. La fuente que hace posible la holografía es el láser. La palabra Láser (Light Amplification by Stimulated Emission of Radiation) significa científicamente traducido «amplificación de la luz mediante emisión estimulada por radiación». El láser es capaz de producir un rayo intenso de luz coherente. Una luz coherente es una luz monocromática con frentes de ondas planas e ininterrumpidas. En el láser los trenes de onda deben avanzar continuamente. Una luz monocromática es una luz de un sólo color, de una sóla frecuencia.

Un holograma es un tipo especial de fotografía. Esa fotografía es registrada sobre un material fotosensible de elevado contraste. Pero a la hora de hacer el holograma, a diferencia de la fotografía, no se utiliza un objetivo. El holograma contiene datos referidos a la intensidad, la amplitud, la longitud de onda y la fase de la luz reflejada por un objeto. La fotografía tradicional únicamente retiene los datos referidos a la intensidad de la luz. Por lo tanto, con la holografía, la profundidad de campo y la perspectiva lineal dejan paso al registro total del volumen de la realidad. Es un procedimiento que actualmente está tomando vigor, pero que es relativamente antiguo.

Ya es posible también la producción de hologramas generados por ordenador. Una imagen holográfica parece visualmente sólida, pero no tiene solidez física, no se puede tocar, está hecha únicamente para ser vista. Para registrar un holograma hay, pues, tres elementos principales: el láser, el objeto y la placa holográfica.

La luz del láser es dirigida hacia los objetos, que la reflejan en muchas direcciones y algo de ella en la dirección de la placa holográfica. La luz láser es también dirigida directamente sobre la placa holográfica. Es la combinación de estas dos luces la que se registra en la placa de holografía. De esa forma la placa fotográfica especial almacena detalles de la luz proveniente del objeto, su brillo y la distancia que ha recorrido. Una vez expuesta, la placa es revelada y fijada en soluciones químicas para hacer permanente la información registrada. El holograma procesado se parece a un trozo de vidrio coloreado, y no tiene imagen fotográfica visible de los objetos registrados.

La confección de un holograma requiere estabilidad. No simplemente un lugar razonablemente tranquilo, sino un entorno microscópicamente estable. Si se mueve cualquier cosa durante la exposición ya sea el objeto, la placa o el láser no 
se producirá registro o éste será incompleto. Para reducir la posibilidad de movimiento, los hologramas se hacen sobre una mesa estable, que esté aislada de vibraciones. Igualmente, cada elemento óptico debe ser fijado firmemente, y el objeto que se va a registrar debe estar estable. La instalación para registrar un holograma se denomina «cámara» holográfica. Las buenas mesas con su aislamiento antivibratorio pesan varias toneladas, si bien en la actualidad se construyen otras con menos requerimientos.

La técnica cinematográfica, actualmente, persigue la holografía. Cualquier cosa que pueda filmarse puede ser convertida en un estereograma holográfico. Para realizar un estereograma holográfico pueden emplearse técnicas de filmación tales como fundidos, zooms, etc. El problema es que los movimientos de los objetos han de ser lentos. Para hacer un holograma de cine, con objetos móviles, el objeto y la emulsión deben estar iluminados solamente durante un período muy corto por láseres generadores de pulsaciones de alta intensidad de una duración de 20 nanosegundos, y de gran intensidad.

Como toda la escena debe estar iluminada con luz coherente de láser, hasta el momento esto limita la holografía a las escenas de interiores. De momento parece improbable conseguir hologramas de las dimensiones de una pantalla de cine. Al menos aún no se ha encontrado un procedimiento de proyección. La lente de proyección debe ampliar la imagen sin distorsión en los tres ejes y todavía no hay ningún sistema óptico que lo pueda conseguir.

\section{Bibliografía}

- BETTETINI, GIANFRANCO y otros: Las nuevas tecnologías de la comunicación, Paidós, Barcelona, 1995.

- FERNÁNDEZ SÁNCHEZ, Manuel Carlos: Influencias del montaje en el lenguaje audiovisual, Ediciones Libertarias/Prodhufi, Madrid, 1997.

- FRISCH, Karl Von: La biología, Plaza y Janes, Barcelona,1970.

- HUXLEY, Aldous: Un mundo feliz, Plaza y Janes, Barcelona, 1976.

- LANGFORD, Michael J.:Fotografía básica, Omega, Barcelona, 1991.

- REAL ACADEMIA ESPAñOLA: Diccionario de la lengua española, EspasaCalpe, Madrid, 1992.

- VARIOS: Diccionario Enciclopédico Larousse, Planeta, Barcelona, 1990.

\section{Internet}

- DE CASTRO, Alfonso A. (1998): http//www.arrakis.es/ adc

- EURO STEREO FOUNDATION (1998): http//www.members.xoom.com/esf/ index.html

- KLEIN, ALEXANDRE (1998): http//www.Stereoscopy.com 